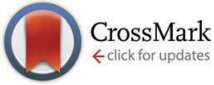

Cite this: Chem. Commun., 2015, 51, 15133

Received 21st July 2015,

Accepted 24th August 2015

DOI: $10.1039 / \mathrm{c5cc06093a}$

www.rsc.org/chemcomm

\section{Continuous and convergent access to vicinyl amino alcohols $\dagger$}

\author{
Tomoya Nobuta, $\ddagger^{a}$ Guozhi Xiao, $\ddagger^{a}$ Diego Ghislieri, ${ }^{a}$ Kerry Gilmore ${ }^{\star^{a}}$ and \\ Peter H. Seeberger*ab
}

Five active pharmaceutical ingredients (APIs) containing the vicinyl amino alcohol moiety were synthesized using a convergent chemical assembly system. The continuous system is composed of four flow reaction modules: biphasic oxidation, Corey-Chaykovsky epoxidation, phenol alkylation, and epoxide aminolysis. Judicious choice of reagents and module order allowed for two classes of $\beta$-amino alcohols, aryl and aryloxy, to be synthesized in good (27-69\%) overall yields.

The chemical synthesis of active pharmaceutical ingredients (APIs) is generally accomplished via a linear batch approach where a single process produces a single compound. Flow chemistry is a conceptual advance that allows for greater control over reaction conditions ${ }^{1}$ and the ability to combine several sequential flow reactors to achieve multi-step processes. ${ }^{2-4}$ Chemical assembly systems $(\mathrm{CAS})^{5}$ are based on telescoping sequential robust reaction units that are linked together in a non-iterative fashion. Multi-step syntheses of a wide range of compounds of similar ${ }^{6}$ or unique ${ }^{5}$ structural cores can be accessed in a divergent fashion (Fig. 1). Here, we report on the application of CAS to convergent syntheses, where two structural variations of a key epoxide intermediate can be trapped in an aminolysis reaction to produce two distinct classes of $\beta$-amino alcohols, including five APIs.

A variety of biologically active natural products, chiral auxiliaries, ligands, and APIs for the treatment of hypertension or as bronchodilators contain $\beta$-amino alcohols as an important structural core. ${ }^{7-9}$ Synthetic approaches to $\beta$-amino alcohols abound,$^{10}$ including amino acid reduction, ${ }^{8 a}$ coupling reactions, $\alpha$-functionalization, ${ }^{11}$ amino-hydroxylation, and epoxide ring opening. ${ }^{12}$ Two classes of pharmaceutically relevant compounds, aryl and aryloxy vicinyl amino

\footnotetext{
${ }^{a}$ Max Planck Institute of Colloids and Interfaces, Am Mühlenberg 1,

14476 Potsdam, Germany. E-mail: kerry.gilmore@mpikg.mpg.de, peter.seeberger@mpikg.mpg.de

${ }^{b}$ Institute of Chemistry and Biochemistry, Freie Universität Berlin, Arnimallee, 22, 14195 Berlin, Germany

$\dagger$ Electronic supplementary information (ESI) available: Characterization data, full experimental procedures, copies of ${ }^{1} \mathrm{H}$ and ${ }^{13} \mathrm{C}$ NMR spectra of all new compounds. See DOI: 10.1039/c5cc06093a

\$ These authors contributed equally to this work.
}

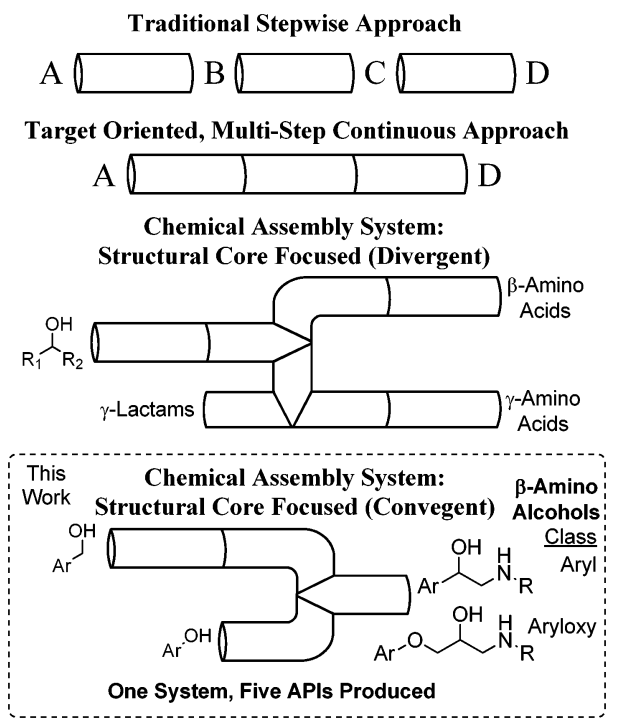

Fig. 1 Comparison of concepts for the chemical synthesis of small molecules.

alcohols, should be accessible via convergent epoxidations followed by a final ring opening with an amine (Fig. 2).

Aryl epoxides should be accessible via a one-to-two step oxidation/Corey-Chaykovsky process. Employing robust and selective biphasic alcohol-oxidation conditions we developed earlier, ${ }^{5}$ the first transformation is readily achieved and thus a continuous Corey-Chaykovsky epoxidation needed to be developed. Using benzaldehyde as a model system, a $0.5 \mathrm{M}$ toluene solution was

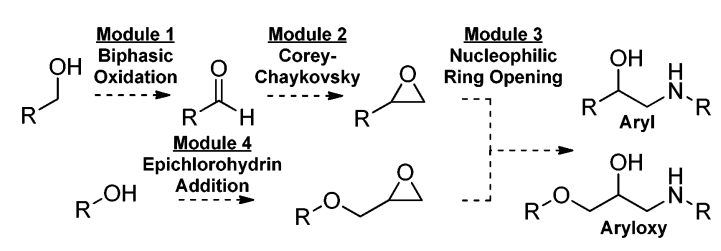

Fig. 2 Convergent synthesis of aryl and aryloxy vicinyl amino alcohols via a concluding epoxide ring opening. 
Table 1 Optimization of Corey-Chykovsky reaction (module 2) in flow ${ }^{a}$

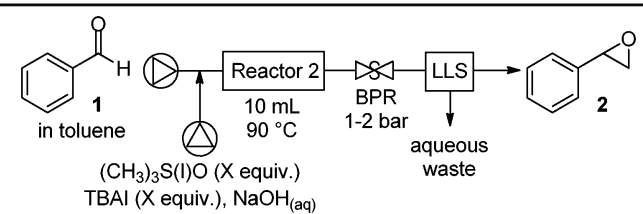

\begin{tabular}{llllll}
\hline Entry & $\mathrm{Me}_{3} \mathrm{SOI}^{b}$ & $\mathrm{NaOH}^{b}$ & $\mathrm{TBAI}^{b}$ & $\begin{array}{l}\text { Residence } \\
\text { time (min) }\end{array}$ & $\begin{array}{l}\text { Conversion } \\
\text { of } \mathbf{1}(\%)\end{array}$ \\
\hline 1 & 1.4 & 1.4 & 0.1 & 24 & 95 \\
2 & 1.7 & 1.7 & 0.1 & 24 & 97 \\
3 & 2.0 & 2.0 & 0.1 & 24 & 96 \\
4 & 1.7 & 1.7 & 0.1 & 40 & 96 \\
5 & 1.7 & 1.7 & 0.1 & 10 & 88 \\
$6^{c}$ & 1.7 & 1.7 & 0.1 & 24 & 85 \\
7 & 1.7 & 1.7 & 0.0 & 24 & 79
\end{tabular}

${ }^{a}$ Pump A: benzaldehyde $(\mathbf{1})$ in toluene $(0.5 \mathrm{M})$, flow rate: $0.083 \mathrm{~mL}$ $\min ^{-1}$. Pump B: $\left(\mathrm{CH}_{3}\right)_{3} \mathrm{~S}$ (I)O (1.7 equiv., $\left.0.21 \mathrm{M}\right), \mathrm{NaOH}$ (1.7 equiv.), TBAI (0.1 equiv.) in water, flow rate: $0.33 \mathrm{~mL} \mathrm{~min}{ }^{-1}$, reactor size: $10 \mathrm{~mL}$, pressure: $1-2$ bar. ${ }^{b}$ Equivalents with respect to benzaldehyde. ${ }^{c}$ Reaction run at $60{ }^{\circ} \mathrm{C}$. BPR: back pressure regulator, LLS: liquid/liquid separator. For full experimental details, see ESI.

mixed with an aqueous solution of trimethylsulfonium iodide $\left(\left(\mathrm{CH}_{3}\right)_{3} \mathrm{~S}(\mathrm{I}) \mathrm{O}\right)$, sodium hydroxide $(\mathrm{NaOH})$, and a substoichiometric amount of phase transfer catalyst (tetrabutylammonium iodide (TBAI)). The resulting biphasic solution was passed through a $10 \mathrm{~mL}$ reactor held at $90{ }^{\circ} \mathrm{C}$ at a pressure of 2 bar. Clean conversions to styrene oxide were observed with $\left(\mathrm{CH}_{3}\right)_{3} \mathrm{~S}(\mathrm{I}) \mathrm{O}$ and $\mathrm{NaOH}$ in excess (1.4-2 equiv., Table 1 entries 1-3) after 24 minutes. Shorter reaction times, temperature, and the absence of TBAI resulted in decreased conversion (entries 5-7).

Using optimized conditions ( $97 \%$, entry 2), we next turned to the amine ring-opening. While epoxide opening traditionally employed Lewis acids (LA), the elevated pressures and temperatures during microwave $^{13}$ and flow ${ }^{12}$ transformations allow for clean reactions without LA catalysts. We aimed to combine epoxidation and ring opening by modifying established flow conditions. ${ }^{12}$ Thus, the crude toluene solution containing styrene oxide was mixed with ${ }^{t} \mathrm{BuNH}_{2}$ in toluene/ethanol $(2: 1)$. With three equivalents of amine, good conversion to the desired regioisomer was observed after 50 minutes at $150{ }^{\circ} \mathrm{C}$ (Table 2, entry 1). Increasing the amount of amine to seven equivalents resulted in the highest regioselectivity at essentially full conversion (entry 3). Decreasing both the temperature and time resulted in lower conversions (entries 4 and 5). No product resulting from the bis-alkylation of the amine was observed under these conditions.

Modules 2 and 3 were connected with the help of a modified Jensen liquid-liquid separator, ${ }^{14}$ allowing for the toluene phase exiting the epoxidation to be used directly in the ring opening reaction. Thus, after a total residence time of 74 minutes, benzaldehyde was transformed into 2-(tert-butylamino)-1phenylethanol 3 in 57\% yield following off-line crystallization. A range of haloarenes reacted with isopropyl or tert-butyl amine without intermediate purification using the modular set-up. Moderate to good yields of the desired regioisomer were observed following product crystallization (Fig. 3). Tulobuterol, a $\beta_{2}$-adrenergic agonist used to treat asthma, ${ }^{15}$ was targeted. After passing 2-chloro benzyl alcohol through modules 1, 2, and
Table 2 Optimization of aminolysis (module 3) in flow

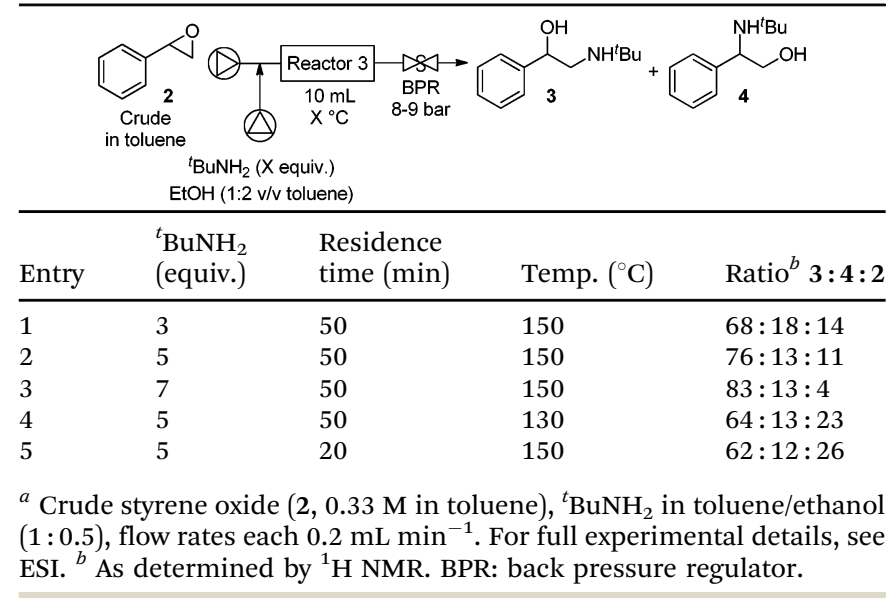

3 - with separators between modules $1 / 2$ and $2 / 3$ - the API was obtained in $27 \%$ yield (Fig. 3 ).

A number of hypertension medications such as propranolol, alprenolol, and metoprolol ${ }^{16}$ contain the aryloxy $\beta$-amino alcohol motif. These targets were selected to expand the scope of the modular flow synthesis of vicinyl amino alcohols. Typical phenol alkylations require a large excess of epichlorohydrin equivalents ${ }^{17}$ in the presence of an inorganic base. ${ }^{18}$ However, homogeneous solutions would facilitate the development of a flow process. A biphasic solution, obtained by mixing aqueous sodium hydroxide solution with a phenol in neat epichlorohydrin, should provide the desired aryloxy epoxide (Table 3).

The sodium hydroxide solution (1.95 M, 1.3 equiv.) is combined with phenol in three equivalents of neat epichlorohydrin via a T-mixer and passed through a reactor $(1 \mathrm{~h}$ reaction time at $\left.35{ }^{\circ} \mathrm{C}\right)$. Two major alkylation products $(\mathbf{1 0}, \mathbf{1 1})$ were observed in roughly a $2: 1$ ratio, with the desired epoxide 10 obtained in $56 \%$ (Table 3, entry 1). Addition of substoichiometric amounts of PTC resulted in an increased conversion of the intermediate halohydrin (11) into the desired product (entry 2). At a reaction temperature of $45{ }^{\circ} \mathrm{C}, 10$ was obtained in $86 \%$ yield while no intermediate halohydrin was observed (entry 3). At higher temperatures, a diol was formed by sodium hydroxide mediated ring opening of the epoxide. ${ }^{19}$ Reducing the excess of epichlorohydrin to two equivalents (entry 5, final conditions) had no effect, while a further reduction of the reagent to one equivalent yielded sizable amounts

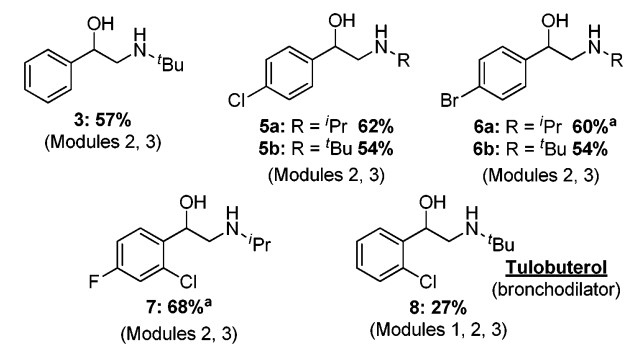

Fig. 3 Aryl vicinyl amino alcohols produced by continuous synthesis. a Residence time of Corey-Chaykovsky reaction is $40 \mathrm{~min}$. See ESI $\dagger$ for full experimental details. 
Table 3 Optimization of the phenol alkylation in flow ${ }^{a}$

\begin{tabular}{|c|c|c|c|c|c|c|c|}
\hline \multirow[b]{2}{*}{ Entry } & \multirow{2}{*}{$\begin{array}{l}\text { Epichlorohydrin } \\
\text { (equiv.) }\end{array}$} & \multirow{2}{*}{$\begin{array}{l}\text { Temp. } \\
\left({ }^{\circ} \mathrm{C}\right)\end{array}$} & \multirow{2}{*}{$\begin{array}{l}\text { TBACl } \\
\text { (equiv.) }\end{array}$} & \multirow{2}{*}{$\begin{array}{l}\text { Residence } \\
\text { time (min) }\end{array}$} & \multicolumn{3}{|c|}{ Yield (\%) } \\
\hline & & & & & 10 & 11 & 12 \\
\hline 1 & 3 & 35 & - & 60 & 56 & 24 & - \\
\hline 2 & 3 & 35 & 0.1 & 60 & 68 & 15 & - \\
\hline 3 & 3 & 45 & 0.1 & 60 & 86 & - & - \\
\hline 4 & 3 & 45 & 0.1 & 46 & 80 & 8 & - \\
\hline 5 & 2 & 45 & 0.1 & 60 & 85 & - & - \\
\hline 6 & 1 & 45 & 0.1 & 60 & 65 & - & 21 \\
\hline
\end{tabular}

${ }^{a}$ Pump A: phenol, TBACl and epichlorohydrin, pump B: $1.95 \mathrm{M} \mathrm{NaOH}$ (1.3 equiv.), reactor size: $4 \mathrm{~mL}$. For full experimental details, see ESI.

of dimer 12 (entry 6). Shortening the residence time in the reactor to 46 minutes resulted in incomplete conversion (entry 4).

Using this method, chiral aryloxy epoxides can be generated efficiently. When enantiopure epichlorohydrin is reacted using the conditions described above, the reaction proceeds with 93.7\% ee (Fig. 4).

Module 4 depends on the solubility of the intermediate aryloxide in the biphasic solution. In cases where a precipitate forms, as occurred during the synthesis of metoprolol 20, module 4 can split into a two-stage alkylation. ${ }^{20-22}$ Phenol was efficiently alkylated at $110{ }^{\circ} \mathrm{C}$ after 60 minutes when epichlorohydrin served as solvent (3.1 M, 2 equiv.). By mixing the resulting solution with aqueous $\mathrm{NaOH}$ at $45{ }^{\circ} \mathrm{C}, 84 \%$ of the desired epoxide could be obtained after only 30 minutes (Fig. 5). ${ }^{19}$

With a reliable process for the procurement of epoxide 10 in hand, the aminolysis module was connected (Table 2). Alkyl epoxides proved more active than aryl epoxides such that the ring opening proceeded at lower temperatures and shorter reaction times (Table 4). The epoxide solution was converted in just 20 min when mixed with five equivalents of isopropylamine in ethanol at $120{ }^{\circ} \mathrm{C}$ (entry 4). The reaction proceeds efficiently at $100{ }^{\circ} \mathrm{C}$, but requires longer residence times (entry 2). Only one regioisomer and no amine dialkylation product were observed.

Finally, modules 3 and 4 were combined to yield the final sequence. The biphasic solution exiting module 4 is mixed with toluene. The toluene phase is removed using a membrane-based separator $^{14}$ and directly fed into module 3. Amino alcohol 16 was obtained in $48 \%$ yield from phenol, following off-line crystallization (Fig. 6). Several active pharmaceutical ingredients were prepared based on a judicious choice of starting materials. Racemic and chiral aryloxy $\beta$-amino alcohols can be prepared

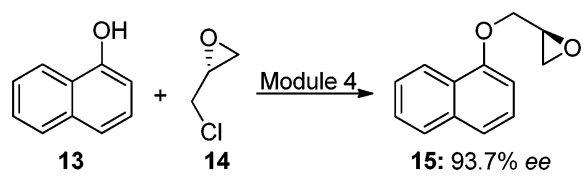

Fig. 4 Synthesis of (S)-2-((naphthalen-1-yloxy)methyl)oxirane using enantiopure $(R)$-epichlorohydrin.

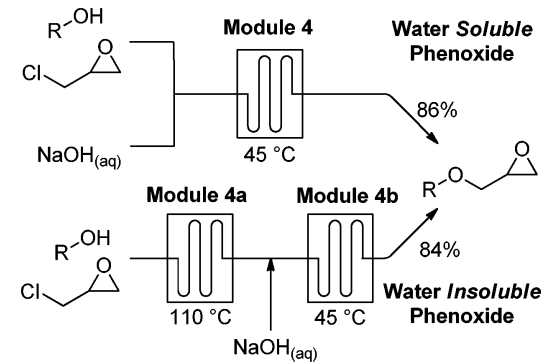

Fig. 5 To accommodate water-soluble and insoluble phenoxides, two variants of module 4 , were implemented.

Table 4 Optimization of aminolysis in flow ${ }^{a}$

\begin{tabular}{|c|c|c|c|}
\hline \multicolumn{4}{|c|}{$\begin{array}{c}{ }^{i} \mathrm{PrNH}_{2} \text { (5 equiv.) } \\
\text { EtoH } \\
\end{array}$} \\
\hline Entry & $T\left({ }^{\circ} \mathrm{C}\right)$ & Residence time (min) & Conversion (\%) \\
\hline 1 & 80 & 30 & 78 \\
\hline 2 & 100 & 30 & 100 \\
\hline 3 & 100 & 20 & 85 \\
\hline 4 & 120 & 20 & 100 \\
\hline
\end{tabular}

${ }^{a}$ Pump A: epoxide in toluene, pump B: isopropylamine ( 5 equiv.) in EtOH, reactor size: $20 \mathrm{~mL}$, BPR: 5.2 bar. For full experimental details, see ESI. BPR: back pressure regulator.

including propranolol $(\mathbf{1 7}, 51 \%),{ }^{23}$ used to treat hypertension, ${ }^{24}$ alprenolol (18, 42\%), an angina pectoris medication, ${ }^{25}$ and the hypertension drugs bupranolol $(\mathbf{1 9}, 69 \%),{ }^{26}$ as well as metoprolol (20, 69\%).

Described is the development of a convergent chemical assembly system consisting of four modules that reliably produces aryl and aryloxy $\beta$-amino alcohols in good yields. Modular flow units include biphasic oxidations, ${ }^{5}$ Corey-Chaykovsky epoxidations, aryloxy alkylations, and epoxide aminolysis. ${ }^{12}$ Aqueous in-line workup using liquid-liquid extractors resulted in continuous processes without intermediate purification. Starting from phenols or benzyl alcohols five active pharmaceutical ingredients for the treatment of hypertension, agina pectoris, and bronchiodilation were produced. Enantiopure aryloxy $\beta$-amino alcohols can be prepared by starting from $R / S$ epichlorohydrin.

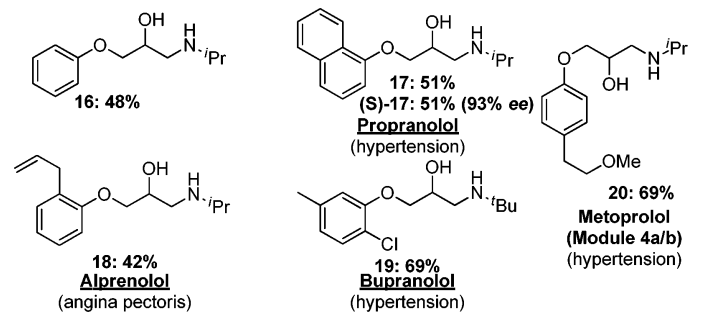

Fig. 6 Overview over aryloxy vicinyl amino alcohols produced by continuous synthesis. 


\section{Notes and references}

1 (a) I. W. Davies and C. J. Welch, Science, 2009, 325, 701; (b) J.-I. Yoshida, Y. Takahashi and A. Nagaki, Chem. Commun., 2013, 49, 9896; (c) L. Malet-Sanz and F. Susanne, J. Med. Chem., 2012, 55, 4062.

2 For recent selected reviews about flow chemistry, see: $(a)$ V. Hessel, Chem. Eng. Technol., 2009, 32, 1655; (b) D. Webb and T. F. Jamison, Chem. Sci., 2010, 1, 675; (c) R. L. Hartman, J. P. McMullen and K. F. Jensen, Angew. Chem., Int. Ed., 2011, 50, 7502; (d) N. G. Anderson, Org. Process Res. Dev., 2012, 16, 852; (e) D. T. McQuade and P. H. Seeberger, J. Org. Chem., 2013, 78, 6384; $(f)$ K. S. Elvira, X. C. Solvas, R. C. R. Wootton and A. J. deMello, Nat. Chem., 2013, 5, 905; ( $g$ ) S. V. Ley, D. E. Fitzpatrick, R. J. Ingham and R. M. Myers, Angew. Chem., Int. Ed., 2015, 54, 3449.

3 J. C. Pastre, D. L. Browne and S. V. Ley, Chem. Soc. Rev., 2013, 42, 8849. 4 For select examples, see: $(a)$ M. D. Hopkin, I. R. Baxendale and S. V. Ley, Chem. Commun., 2010, 46, 2450; (b) A. R. Bogdan, S. L. Poe, D. C. Kubis, S. J. Broadwater and D. T. McQuade, Angew. Chem., 2009, 121, 8699 (Angew. Chem., Int. Ed., 2009, 48, 8547); (c) M. Viviano, T. N. Glasnov, B. Reichart, G. Tekautz and C. O. Kappe, Org. Process Res. Dev., 2011, 15, 858; (d) D. R. Snead and T. F. Jamison, Chem. Sci., 2013, 4, 2822; (e) L. Kupracz and A. Kirschning, Adv. Synth. Catal., 2013, 355, 3375; $(f)$ M. D. Hopkin, I. R. Baxendale and S. V. Ley, Org. Biomol. Chem., 2013, 11, 1822; $(g)$ T. Gustafsson, H. Sörensen and F. Pontén, Org. Process Res. Dev., 2012, 16, 925; $(h)$ F. Lévesque and P. H. Seeberger, Angew. Chem., 2012, 124, 1738 (Angew. Chem., Int. Ed., 2012, 51, 1706); (i) D. Kopetzki, F. Lévesque and P. H. Seeberger, Chem. - Eur. J., 2013, 19, 5450; $(j)$ D. R. Snead and T. F. Jamison, Angew. Chem., Int. $E d ., 2015,54,983$; (k) C. A. Correia, K. Gilmore, D. T. McQuade and P. H. Seeberger, Angew. Chem., Int. Ed., 2015, 54, 4945.

5 D. Ghislieri, K. Gilmore and P. H. Seeberger, Angew. Chem., Int. Ed., 2014, 54, 678.

6 K. Gilmore, D. Kopetzki, J. W. Lee, Z. Horváth, D. T. McQuade, A. Seidel-Morgenstern and P. H. Seeberger, Chem. Commun., 2014, 50, 12652.

7 (a) D. J. Ager, I. Prakash and D. R. Schaad, Chem. Rev., 1996, 96, 835; (b) I. Gallou and C. H. Senanayake, Chem. Rev., 2006, 106, 2843; (c) J. L. Vicario, D. Badia, L. Carrillo, E. Reyes and J. Etxebarria, Curr. Org. Chem., 2005, 9, 219; (d) F. Fache, E. Schulz, M. L. Tommasino and M. Lemaire, Chem. Rev., 2000, 100, 2159.

8 (a) D. J. Ager, I. Prakash and D. R. Schaad, Chem. Rev., 1996, 96, 835;

(b) E. J. Corey and F. Zhang, Angew. Chem., Int. Ed., 1999, 38, 1931; (c) P. O'Brien, Angew. Chem., Int. Ed., 1999, 38, 326; (d) D. S. Bose and A. V. Narsaiah, Bioorg. Med. Chem., 2005, 3, 627.
9 Amino alcohol drugs such as Metoprolol, Atenolol were among the Top 200 brand name drugs by total prescriptions in 2012, see: N. A. McGrath, M. Brichacek and J. T. Njardarson, J. Chem. Educ., 2010, 87, 1348.

10 S. C. Bermeier, Tetrahedron, 2000, 56, 561.

11 (a) S. Sohda, M. Fujimoto, T. Tamegai and N. Hirose, J. Med. Chem., 1979, 22, 279; (b) E. Babad, N. I. Carruthers, R. S. Jaret and M. Steinman, Synthesis, 1988, 966.

12 M. W. Bedore, N. Zaborenko, K. F. Jensen and T. F. Jamison, Org. Process Res. Dev., 2010, 14, 432.

13 (a) H. Desai, B. R. D'Souza, D. Foether, B. F. Johnson and H. A. Lindsay, Synthesis, 2007, 902; (b) A. Robin, F. Brown, N. Bahamontes-Rosa, B. Wu, E. Beitz, J. F. J. Kun and S. L. Flitsch, J. Med. Chem., 2007, 50, 4243; (c) P. Lidström, J. Tierney, B. Wathey and J. Westman, Tetrahedron, 2001, 57, 9225.

14 For details of the modification, see ESI. $\dagger$ For the original description of the membrane-based separator, see J. G. Kralj, H. R. Sahoo and K. F Jensen, Lab Chip, 2007, 7, 256.

15 T. Ichikawa and H. Sugiura, Res. Rep. Transdermal Drug Delivery, 2013, $2,9$.

16 M. Sittig, Pharmaceutical manufacturing encyclopedia, Noyes publications, 2nd edn, 1988, vol. 1.

17 Typical conditions utilize epichlorohydrin in as much as $20 \times$ excess, see: ref. 16, p. 110.

18 S. Srivastava, K. Bhandari, G. Shankar, H. K. Singh and A. K. Saxena, Med. Chem. Res., 2004, 13, 631.

19 See ESI $\dagger$ for further details.

20 (a) K. Kawamura, T. Ohta and G. Otani, Chem. Pharm. Bull., 1990, 38, 2092; (b) K. Sakaguchi, Y. Shiomi, T. Kitamura, Y. Takehira, M. Koden, T. Kuratate and K. Nakagawa, Chem. Lett., 1991, 1109.

21 For the use of CsF as catalyst, see: K. Kitaori, Y. Furukawa, H. Yoshimoto and J. Otera, Tetrahedron, 1999, 55, 14381.

22 For the achiral synthesis of aryl glycidyl ethers, see: Z.-Z. Liu, H.-C. Chen, S.-L. Cao and R.-T. Li, Synth. Commun., 1994, 24, 833.

23 This yield compares favourably with a comparable two-step batch process from 4-(benzyloxy)naphthalen-1-ol, see: T. Kumamoto, N. Aoyama, S. Nakano, T. Ishikawa and S. Narimatsu, Tetrahedron: Asymmetry, 2001, 12, 791.

24 "Propranolol hydrochloride", Monograph, The American Society of Health-System Pharmacists, retrieved Jan 1, 2015.

25 J. B. Hickie, Med. J. Aust., 1970, 2, 268.

26 M. R. Candelore, L. Deng, L. Tota, X.-M. Guan, A. Amend, Y. Liu, R. Newbold, M. A. Cascieri and A. E. Weber, J. Pharmacol. Exp. Ther., 1999, 290, 649. 